\title{
Internal Carotid Artery Septa in Sickle Cell Disease: Risk Factor for Stroke?
}

\author{
Pranshu Sharma, Mayank Goyal, Ali M. Al-Khathaami, Andrew Demchuk
}

Can. J. Neurol. Sci. 2008; 35: 378-380

Sickle cell disease is a hemoglobinopathy occurring due to replacement of valine for glutamic acid at the sixth position of the beta globin chain. The altered hemoglobin structure makes it prone for polymerization during hypoxic and infective stress. Polymerization of the hemoglobin molecule leads to sickling of the red blood cells in the vessels causing thrombosisvasoocclusive crises. Although abdomen and extremities are more often involved, silent cerebral infarcts and stroke can occur in up to $25-29 \%$ of patients ${ }^{1,2}$ and is the major cause of morbidity and mortality.

Cerebral angiographic findings of sickle cell disease include stenosis and occlusion of the internal carotid or middle cerebral arteries, ${ }^{3}$ moya-moya pattern ${ }^{4}$ (stenosis/occlusion of supraclinoid internal carotid artery with dilated lenticulostriate vessels), arterial dissections ${ }^{5}$ and small vessel vasculitis. ${ }^{6}$ We describe an unusual angiographic finding of septa in bilateral internal carotid artery bulbs along with another septum in the cavernous segment of the left internal carotid artery in a patient of sickle cell disease. Such septa have rarely been reported in the internal carotid and common carotid arteries ${ }^{7-11}$ but never in the setting of sickle cell disease. It is likely that these septa were an additional risk factor for ischemic stroke in our patient.

\section{Case Report}

A 29-year-old woman with sickle cell disease presented with cognitive decline, unstable gait and slurred speech of one year duration. She was diagnosed with sickle cell disease at the age of two and had had multiple transfusions and sickle cell crises. She had her first stroke at the age of 15 years in the form of left-sided weakness. She also had seizures for the past two years which were well-controlled on lamotrigine. On examination, she had slurred speech, spastic gait and minor left spastic hemiparesis. She had cognitive impairment involving visual, spatial and executive functions.

Non-contrast enhanced computed tomography (CT) revealed mild atrophy of right fronto-parietal regions with hypodensity of the underlying white matter. Magnetic resonance imaging (MRI) of the head was performed on 1.5T magnet (Siemens, Erlangen). Fluid attenuated inversion recovery (FLAIR) images confirmed the CT findings showing mild right fronto-parietal atrophy. Confluent white matter hyperintensities were noted in periventricular and subcortical white matter suggestive of deep watershed infarcts (Figure 1). The signal abnormalities were more prominent on the right side. No acute infarct was seen on the diffusion weighted images.

Computed tomogram angiography of the head and neck showed normal arch of aorta, origins of neck vessels and bilateral common carotid arteries. The carotid bulbs bilaterally

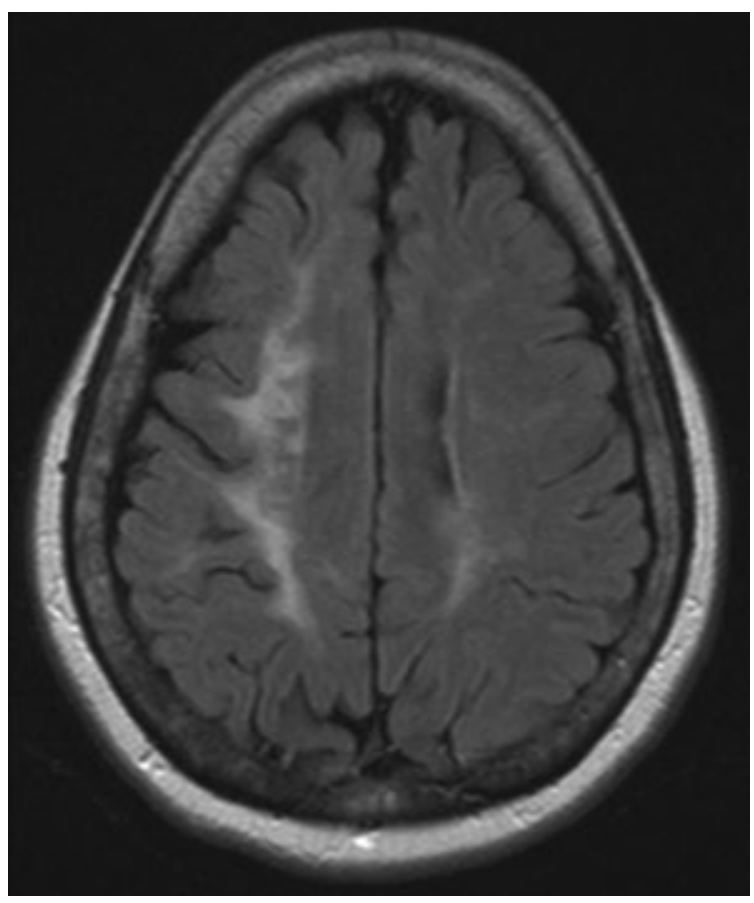

Figure 1. Axial FLAIR MRI shows mild atrophy with confluent periventricular white matter hyperintensity and lacunes in the right fronto-parietal region suggestive of deep watershed infarction. Left periventricular white matter is affected to lesser extent.

showed well-defined horizontal septa measuring $1.3 \mathrm{~mm}$ in thickness and $4 \mathrm{~mm}$ in length on the right side (Figure 2) and $2.3 \mathrm{~mm}$ on the left. The right internal carotid artery (ICA) showed marked attenuation of caliber $1.72 \mathrm{~cm}$ from origin. No filling defect was seen in the bulbs bilaterally other than the septa. No thrombus was seen. No alternating areas of stenosis or dilatation suggesting "string-of-beads" appearance was seen in either

From the Department of Neuroradiology (PS, MG), Calgary Stroke Program, Department of Clinical Neurosciences (AMA, AD), University of Calgary, Foothills Medical Centre, Calgary, Alberta, Canada.

Received August 22, 2007. Final Revisions Submitted February 16, 2008 Reprint requests to: Mayank Goyal, Radiology and Clinical Neurosciences, Department of Diagnostic Imaging, Foothills Medical Centre, 1403 - 29 St NW, Calgary, Alberta, T2N 2T9, Canada. 


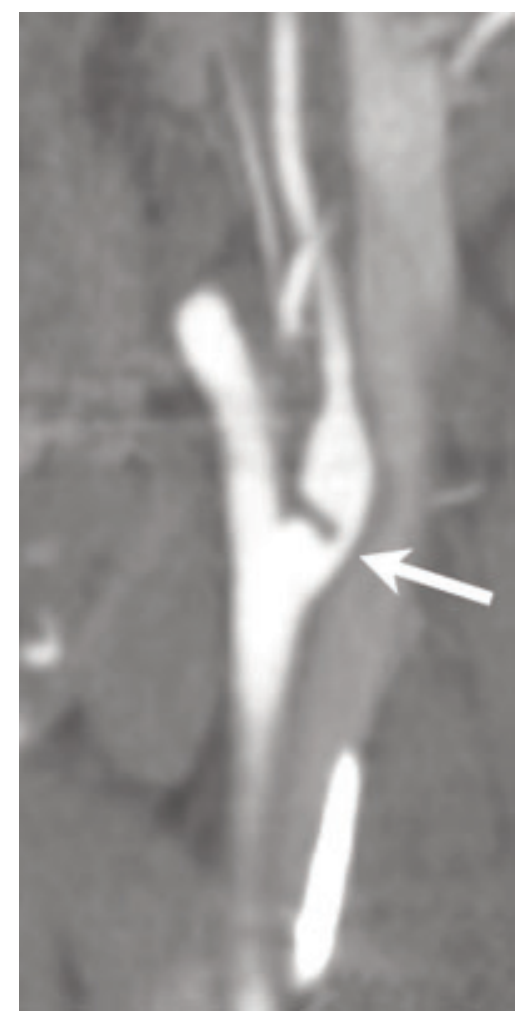

Figure 2. CT angiogram, sagittal reconstruction of right internal carotid artery (ICA) shows a horizontal septum in the bulb of the ICA (arrow). No associated thrombus is seen. The ICA beyond the bulb shows reduced caliber. internal carotid artery. Intracranial CT angiography revealed markedly attenuated right ICA with non-opacification of the distal cavernous and supraclinoid segments. Intracranial course of left ICA, vertebral and basilar arteries was normal.

The digital subtraction angiogram confirmed presence of septa in bilateral ICA bulbs appearing as linear filling defect in the bulbs (Figure 3). Another septa was seen in the cavernous segment of the left ICA. It measured approximately $0.9 \mathrm{~mm}$ in thickness and $3 \mathrm{~mm}$ in length. Again, no thrombus was identified. The right ICA showed very slow antegrade filling and reduced caliber with occlusion of the supraclinoid segment. Moya-moya pattern was seen as dilatation of the lenticulostriate vessels on the right side. Left ICA showed normal caliber and antegrade flow.

We felt that her symptoms were multifactorial but were largely related to chronic cerebrovascular ischemia. The patient was treated with anticoagulation. In view of distal moya-moya pattern, surgical resection of proximal right internal carotid artery septa was not considered. The patient has not had any ischemic event since.

\section{DISCUSSION}

Sickle cell anemia is an autosomal recessive disorder in which abnormal hemoglobin leads to chronic hemolytic anemia with numerous clinical consequences. Substitution of valine for glutamic acid in the sixth position on the beta globin chain leads to formation of abnormal beta chain designated $\beta^{\text {s. The tetramer }}$ of $\alpha_{2}, \beta_{2}^{\mathrm{s}}$ is designated hemoglobin S. When in the deoxy form, hemoglobin $\mathrm{S}$ forms polymers that damage the red blood cell membrane. Initially membrane damage is reversible but following repeated similar episodes the red blood cells become

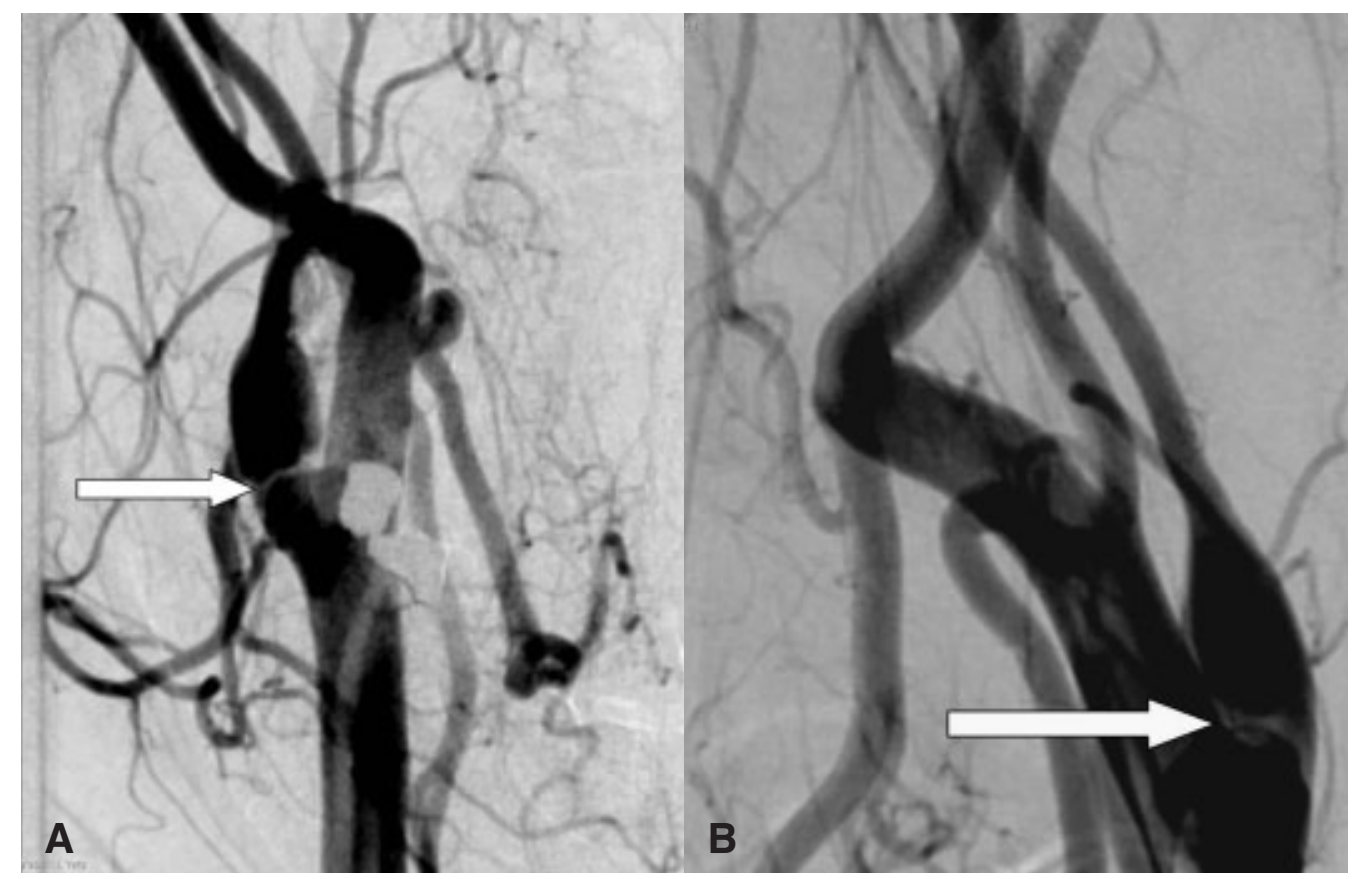

Figure 3. Right common carotid digital subtraction angiogram, A) Lateral and B) Antero-posterior views show horizontal septum in the carotid bulb (arrow) with diminished caliber of the ICA distally. 
irreversibly sickled. The rigid and deformed sickle cell is damaged by mechanical stress during passage through the vasculature resulting in red cell destruction and chronic hemolytic anemia.

Hemoglobin S gene is carried by people of equatorial African, Saudi Arabian and Mediterranean ancestry and sickle cell disease is now widespread in the Americas and Europe. ${ }^{6}$ The disorder has its onset during first year of life. Main clinical features are of chronic hemolytic anemia like jaundice, pigment gallstones, splenomegaly, and poorly healing ulcers over lower tibia. Vaso-occlusion occurs as clusters of sickled red blood cells occlude the microvasculature of the organs involved. Common sites of vaso-occlusion include the bones and the chest. Cerebral arterial thrombosis may occur in up to $25 \%$ of homozygous patients. ${ }^{1}$ Sickling of red blood cells in the capillaries may lead to coagulation and retrograde thrombosis of small vessels. In the larger vessels, repeated episodes of adhesion of sickled red blood cells to the endothelium at sites of bifurcation and shear injury by rapidly flowing blood cause endothelial injury leading to intimal hyperplasia. ${ }^{12}$ The intracranial segment of the ICA is most commonly affected. The lenticulostriate arteries may provide collateral blood supply and enlarge giving rise to moyamoya pattern. ${ }^{1}$

The clinical presentations of patients with cerebrovascular disease include clinical stroke, transient ischemic attacks, seizures and headache. Cognitive difficulties, subtle transient ischemic attacks and seizures can occur in patients with covert brain damage due to silent infarctions in the anterior and posterior watershed areas. Subjects with silent infarcts are also at increased risk of stroke. ${ }^{2}$ Neuroimaging reveals acute ischemic lesions in patients with clinical stroke, abnormality in the basal ganglia, or deep white matter or grey matter of the watershed zones. Angiography often shows underlying risk factors like stenosis and occlusion of the internal carotid or middle cerebral arteries, moya-moya pattern (stenosis/occlusion of supraclinoid ICA with dilated lenticulostriate vessels), arterial dissections and small vessel vasculitis. ${ }^{6}$

Our patient had risk factors in the form of supraclinoid ICA stenosis and moya-moya pattern. Additionally, we found presence of septa in the internal carotid arteries.

These septa are often incidental findings with no associated symptoms. Rarely, however, they are associated with thrombi and ischemic symptoms. Of the few that have been surgically resected the only pathological correlate has been fibromuscular dysplasia (FMD) found in one of the three cases reported by Kubis et $\mathrm{al}^{7}$ and in the cases reported by Morgenlander et al, ${ }^{8}$ So et $\mathrm{al}^{9}$ and Rainer et al. ${ }^{10}$ Histologic evaluation of the surgical specimen in these cases has shown intimal hyperplasia ${ }^{7} /$ fibroplasias, ${ }^{8,9}$ medial fibromuscular dysplasia. ${ }^{10}$ Most asymptomatic septa, however, have no imaging features of FMD.

Fibromuscular dysplasia is a nonatherosclerotic and noninflammatory arteriopathy that affects the smooth muscle and fibrous tissue of small and medium-sized arteries. Its prevalence is $0.5 \%$ to $0.7 \%$ by angiography. ${ }^{7}$ Traditional angiographic feature of FMD is an alteration of expanded and narrowed zones of the arterial lumen, described as a string of beads. Usually, the ICA is involved at the level of the $\mathrm{C} 1$ to $\mathrm{C} 2$ vertebrae, whereas the proximal ICA is usually spared.,8

Very few cases of symptomatic proximal internal carotid artery septa have been reported in the English literature. They may be associated with an increased risk of hemodynamic compromise and thromboembolism. ${ }^{8}$ Clinically patients may present with transient ischemic attacks or stroke due to thrombus formation on the septa. ${ }^{7-10}$ Conservative medical therapy is indicated for most of these patients because the available data suggest a benign natural history for this disease. Fibromuscular dysplasia patients with internal carotid artery septa, however, seem to represent a subpopulation in whom the risk of ischemic stroke is higher. It is therefore recommended that surgical treatment should be considered in these patients if medical therapy is unsuccessful. ${ }^{7,8}$

Although there is no literature describing such proximal ICA septa in patients with sickle cell disease, it is interesting to note that in one series all three patients with proximal ICA septa were Africans, ${ }^{7}$ the ethnic group in which sickle cell disease is most common. Of the patients with septa in proximal ICA for whom the ethnicity has been mentioned, about $60-70 \%$ are of black origin. ${ }^{7}$ Thus, associated presence of FMD or intimal hyperplasia due to endothelial injury ${ }^{12}$ may be the possible etiologies of the septa in our case.

In summary, we present a case of sickle cell disease with horizontal septa in bilateral internal carotid arteries. Presence of septa has been associated with increased risk of thromboembolic events. It is likely that these septa represent additional risk factor for stroke in the present case.

\section{REFERENCES}

1. Ohene-Frempong K, Weiner SJ, Sleeper LA, Miller ST, Embury S, Moohr JW, et al. Cerebrovascular accidents in sickle cell disease: rates and risk factors. Blood. 1998;91:288-94.

2. Pegelow CH, Macklin EA, Moser FG, Wang WC, Bello JA, Miller $\mathrm{ST}$, et al. Longitudinal changes in brain magnetic resonance imaging findings in children with sickle cell disease. Blood. 2002;99:3014-8

3. Gerald B, Sebes JI, Langston JW. Cerebral infarction secondary to sickle cell disease: arteriographic findings. Am J Roentgenol. 1980;134:1209-12.

4. Dobson SR, Holden KR, Nietert PJ, Cure JK, Laver JH, Disco D, et al. Moyamoya syndrome in childhood sickle cell disease: a predictive factor for recurrent cerebrovascular events. Blood. 2002;99:3144-50.

5. Kirkham FJ, Hewes DK, Prengler M, Wade A, Lane R, Evans JP. Nocturnal hypoxemia and central nervous system events in sickle cell disease. Lancet. 2001;357:1656-9.

6. Kirkham FJ. Therapy insight: stroke risk and its management in patients with sickle cell disease. Nature Clinical Practice Neurology. 2007;3(5):264-78.

7. Kubis N, Von Langsdorff D, Petitjean C, Brouland JP, Guichard JP, Chapot R, et al. Thrombotic carotid megabulb: fibromuscular dysplasia, septa, and ischemic stroke. Neurology. 1999; 52(4):883-6.

8. Morgenlander JC, Goldstein LB. Recurrent transient ischemic attacks and stroke in association with an internal carotid artery web. Stroke. 1991;22:94-8.

9. So EL, Toole JF, Moody DM, Challa VR. Cerebral embolism from septal fibromuscular dysplasia of the common carotid artery. Ann Neurol. 1979;6:75-8.

10. Rainer WG, Cramer GG, Newby JP, Clarke JP. Fibromuscular hyperplasia of the carotid artery causing positional cerebral ischemia. Ann Surg. 1968;167:444-6.

11. Matsunaga, N, Hayashi K, Morikawa M. Segmental septa in Takayasu arteritis of the carotid artery. Am J Roentgenol. 1993;160(1):212-3.

12. Moritani T, Numaguchi Y, Lemer NB, Rozans MK, Robinson AE, Hiwatashi A, et al. Sickle cell cerebrovascular disease usual and unusual findings on MR imaging and MR angiography. Journal of Clin Imaging. 2004; 28(3):173-86. 